\title{
The state and importance of motorcycle injuries in progression with trauma etiology
}

\author{
Nadir Ozkayin ${ }^{1 *}$, Erdem Kaan ${ }^{2}$, Kemal Aktuglu ${ }^{1}$
}

\begin{abstract}
Objective: Motorcycle injuries have shown a progression in last years in trauma patients admitted to our clinic. The aim of this study is to evaluate statistically whether the motorcycle accidents incidence is really has a progression or not.

Method: The study involved 180 patients ( 87 women, 93 men) operated for the fractures after a motorcycle crash between the first six months of 2002 and 2007. The injury patterns have been investigated if there was a significant increase or not. The mean age was 45.2 years (min. 1year-max. 87 years). In Group I; 50 patients (22 women, $28 \mathrm{men}$ ) were included which operated in the first 6 months of 2002. The mean age was 44.8 years (min.1 year-max. 85 years). In Group II; 130 patients (65 women, 65 men) were included which operated in the first 6 months of 2007. The mean age was 45.7 (min. 3 years-max. 87 years).

Results: We compared two groups and found a significant 3.425 increase in motorcycle injuries contrary to 0.075 decreases in falls, 0.023 decrease in traffic accidents within the vehicle, 0.013 decreases in traffic accidents out of the vehicle, 0.616 decreases in sports injuries, 0.25 decreases in gunshot injuries. This increase in motorcycle injuries is statistically significant.

Conclusion: We have found significant increase in motorcycle injuries statistically. The importance of this, it affects younger population, and they bring out high morbidity. Since; we think that motorcycle injuries must be stated especially in literatures. We must warn our colleagues to state these injuries, and must take precautions against this problem.
\end{abstract}

Key Words: trauma etiology; motorcycle injury

\section{Introduction}

Major causes of trauma lead to fractures in the human body are; falls, traffic accidents, shotgun wounds, and sports injuries. Distribution of these etiologies may vary according to the age group, geographic conditions, socio economic status of the population. As the years pass, these etiologies may show an increase or decrease. In addition, new causes will show up due to the developing technologies. While low-energy traumas like simple falls affect the older population, high-energy traumas like falls from height affect the younger population.

Lower socio economic population in low-income and middle-income countries (pedestrians, motorcyclists, passengers in buses and trucks) are under higher risk of morbidity, and mortality due to the traffic injuries because of their capacity of purchase (use mass transportation generally). Furthermore, these populations take limited first aid during the injury (1).
Although generally stated as accidents, it is actually intended to say as road traffic injuries (2). This concept includes; accidents within the car and out of the car. The traffic injuries occur out of the car means that the crashes with the pedestrians, cyclists, and motorcyclists. A serious increase in one of these injuries needs to be reviewed individually out of the general conception.

Motorcycle riding, in general, has a reputation for being dangerous (3). Even though people drive any vehicle, faces with injury or death risks, there are remarkable differences in terms of death rates in different driving categories. Especially pedestrianswhich are easily injured- and two wheelers are under higher risk compared to the ones within the car and also they take the major interest (2). 
The motorcycle riders and passengers had a casualty rate nearly fifteen times that of car occupants and they account for $15 \%$ of those are killed or seriously injured (4).

Motorcycle injuries involve multiple anatomical areas including head, abdomen, and thorax, and show a preponderance of musculoskeletal injuries in the form of fractures and dislocations (3, 5-7). Fractures are usually open, contaminated, and markedly comminuted $(3,5)$. A mortality rate of $3-6 \%$ has been reported $(3,4,7)$. Up to $20 \%$ of patients required treatment in an intensive care unit (3). An average of 170 motorcycle crash victims required hospital admission per year in the Yorkshire region alone (4). However, there is no data concerning motorcycle injuries in our country, it is indicated that $\% 17,8$ of the patients admitted to emergencies for trauma (9). Alcohol use has been implicated in up to $70 \%$ of all fatal and non-fatal motorcycle road crashes (3). It has been shown that the risk of fatal injuries in motorcycle crashes are related to the engine capacity of the motorcycle, the size of the vehicle collided against and the direction of collision (4).

The relative risk of being killed or seriously injured (KSI) has been found higher in male and older drivers, greater motorcycle engine size and motorcycle speed, early morning, at the weekends, in the spring and summer, under fine weather, in darkness without street lights, collisions between bus/coach, at uncontrolled junctions (8).

An increase in motorcycle injuries has been observed in trauma cases admitted to our clinic in recent years. Is there really an increase in motorcycle injuries recently, confirming our clinical observation? The purpose of this study is to evaluate statistically the motorcycle injuries incident really increasing or not and also to draw attention of our colleagues and of the society.

\section{Material and Methods}

For this purpose, the injury patterns of the patient population which operated for fractures by the Ege University Orthopaedics \& Traumatology Trauma Group as a result of trauma in first six months of 2002 and in first six months of 2007 are stated, and it is statistically investigated whether there is a significant increase or decrease in trauma etiologies (falls, accidents within the vehicle, accidents out of the vehicle, motorcycle injuries, sports injury, and shotgun injuries) past five years period. Trauma etiologies have been obtained from the patients clinical records. The reason we select the patients only operated in our clinic between these periods was the requirement for obtaining the number and etiological data of the patients more accurate. It is not possible to obtain the real number and etiology of the patients which admitted to emergency service, especially the outpatients. Therefore, the patients we obtain accurate data about them, are considered in this study.

One hundred and eighty patients are included in this study. There were 93 male and 87 female, with a mean age of 45.2 years (min. 1 year-max. 87 years). Group I consisted of 50 patients operated in first six months of 2002, 22 female, 28 male, with a mean age of 44.8 years (min. 1 year-max. 85 years) and Group II consisted of 130 patients operated in first six months of 2007, 65 female, 65 male, with a mean age of 45.7 years (range, min. 3 years-max. 87 years). We studied whether there is a significant change or not in trauma causes of the two groups in the same period of both 2002 and 2007 statistically. Vehicle injuries are analyzed separately as injuries within the car and out of the car in our study. The "vehicle" was ment here is non-motorcycle (bus, truck, etc.) vehicles.

Statistical Analyses: In statistical analyses, Chisquare Test and Ficher Exact Test were utilized. The alfa value was taken as 0.05 in this statistical analysis.

Etiologic distribution and arrangement was: In group I; fall 32 patients $(64 \%)$, injury within the vehicle 8 patients $(16 \%)$, injury out of the vehicle 4 patients $(8 \%)$, sports injury 3 patients $(6 \%)$, motorcycle injury 2 patients $(4 \%)$, and shotgun injury 1 patient $(2 \%)$. In group II; fall 77 patients $(59.2 \%)$, motorcycle injury 23 patients $(17.7 \%)$, injury within the vehicle 16 patients $(12.3 \%)$, injury out of the vehicle 9 patients $(6.9 \%)$, sports injury 3 patients $(2.3 \%)$, and shotgun injury 2 patients $(1.5 \%)$ (Figure 1$)$.

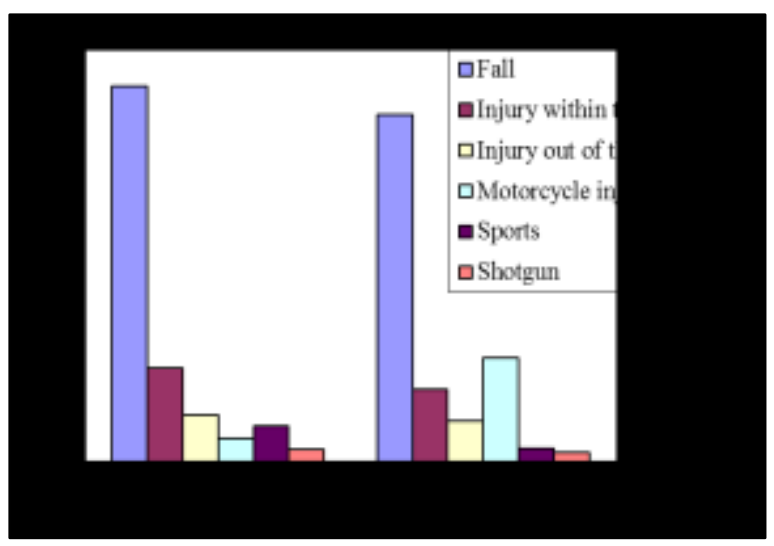

Figure 1: Distribution of trauma etiologies according to the percentages

While motorcycle injury takes the fifth place between trauma etiologies in 2002, it went as high as second place in 2007. When the two groups have been compared; It is established as a 0.075 decrease in falls, 0.023 decrease in injuries within the car, a 0.013 decrease in injuries out of the car, a 0.616 decrease in sports injuries, and a 0.25 decrease in shotgun injuries, compared to an 3.425 times increase in motorcycle injuries. 
Table 1: Numerical and proportional distribution of trauma etiologies of the whole study group (180 patients) according to different age groups and different trauma etiologies

\begin{tabular}{|c|c|c|c|c|}
\hline & $<15$ & $15-45$ & $>45$ & Total \\
\hline \multirow{3}{*}{ Falls } & 13 & 16 & 80 & 109 \\
\hline & $\% 11.93$ & $\% 14.68$ & $\% 73.39$ & $\% 100$ \\
\hline & $\% 68.42$ & $\% 27.59$ & $\% 77.67$ & $\% 60,56$ \\
\hline \multirow{3}{*}{ Injuries Within the Vehicle (IWV) } & 0 & 16 & 8 & 24 \\
\hline & $\% 0$ & $\% 66.67$ & $\% 33.33$ & $\% 100$ \\
\hline & $\% 0$ & $\% 27.59$ & $\% 7.77$ & $\% 13.33$ \\
\hline \multirow{3}{*}{ Injuries Out of the Vehicle (IOV) } & 3 & 6 & 4 & 13 \\
\hline & $\% 23.08$ & $\% 46.15$ & $\% 30.77$ & $\% 100$ \\
\hline & $\% 15.79$ & $\% 10.34$ & $\% 3.88$ & $\% 7.22$ \\
\hline \multirow{3}{*}{ Motorcycle Injuries (MI) } & 1 & 18 & 6 & 25 \\
\hline & $\% 4$ & $\% 72$ & $\% 24$ & $\% 100$ \\
\hline & $\% 5.26$ & $\% 31.03$ & $\% 5.83$ & $\% 13.89$ \\
\hline \multirow{3}{*}{ Shotgun Injuries (ShotgunI) } & 0 & 1 & 2 & 3 \\
\hline & $\% 0$ & $\% 33.33$ & $\% 66.66$ & $\% 100$ \\
\hline & $\% 0$ & $\% 1.72$ & $\% 1.94$ & $\% 1.67$ \\
\hline \multirow{3}{*}{ Sports Injuries (SportI) } & 2 & 1 & 3 & 6 \\
\hline & $\% 33.33$ & $\% 16.67$ & $\% 50$ & $\% 100$ \\
\hline & $\% 10.52$ & $\% 1.72$ & $\% 2.91$ & $\% 3.33$ \\
\hline \multirow{3}{*}{ Total } & 19 & 58 & 103 & 180 \\
\hline & $\% 10.56$ & $\% 32.22$ & $\% 57.22$ & $\% 100$ \\
\hline & $\% 100$ & $\% 100$ & $\% 100$ & $\% 100$ \\
\hline
\end{tabular}

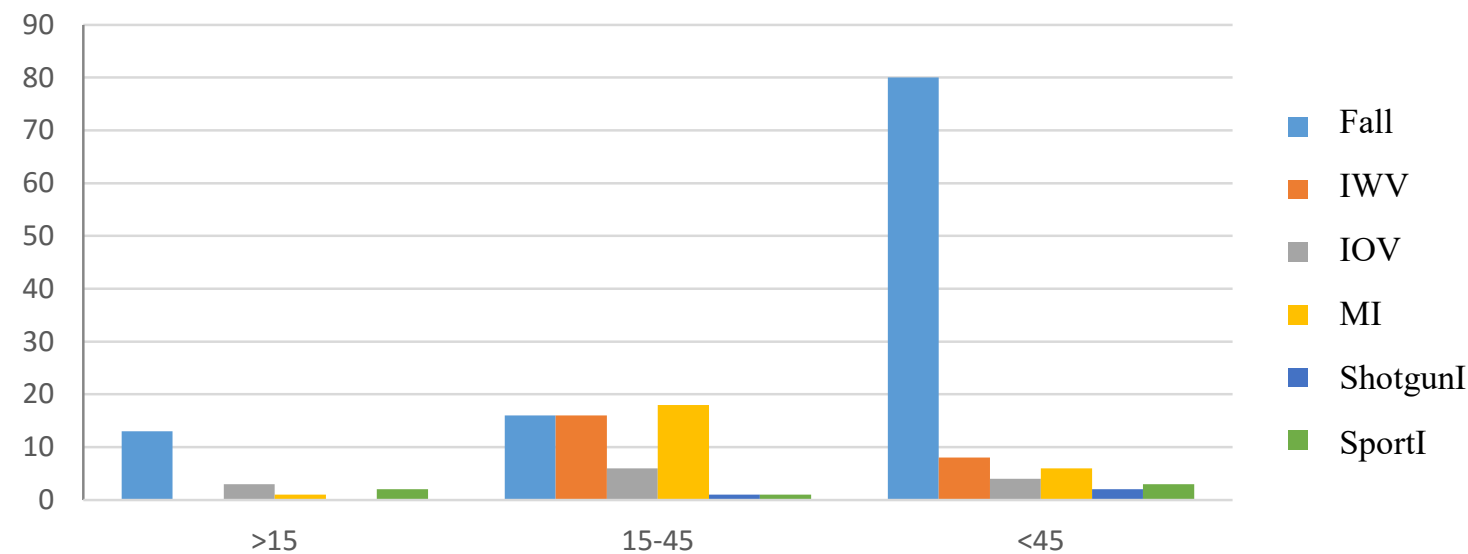

Figure 2: Proportional distribution of trauma etiologies, when investigated according to age groups of total patient population.

These changes in all etiologies except motorcycle injuries have not been found statistically significant $(p=0.057$, Chi-Square test) while, this increase in motorcycle injuries has been found statistically significant according to Ficher Exact test $(p=0.016$, power $=80 \%$ ).

To determine the increase in motorcycles between this time periods, we referred to Transport Authority of İzmir. The number of motorcycles in 2002 was 76612 , while it was 130216 in 2007 . There was a 1.7 increase in the number of motorcycles at that period of time.

In the whole group of 180 patients as seen in figure 2; 109 patients were exposed to fall $(60.56 \%), 24$ patients were exposed to injuries within the vehicle
(13.33), 13 patients were exposed to injuries out of the car $(7.22 \%), 6$ patients were exposed to sports injury $(3.33 \%), 25$ patients were exposed to motorcycle injury $(13.89 \%)$, and 3 patients were exposed to shotgun injuries $(1.67 \%)$. When this data reviewed according to age groups; from 19 patients under 15 years of age, 13 were exposed to fall $(68.42 \%), 3$ were exposed to injury out of the vehicle $(15.79 \%), 2$ were exposed to sports injury $(10.52 \%)$, and 1 was exposed to motorcycle injury $(5.26 \%)$. There was no injury within the vehicle and no shotgun injury. From 58 patients between 15-45 years of age group, 18 were exposed to motorcycle injury $(31.03 \%), 16$ were exposed to fall $(27.59 \%), 16$ were exposed to injury within the vehicle $(27.59 \%)$, 
6 were exposed to injury out of the vehicle $(10.34 \%)$, 1 was exposed to sports injury $(1.72 \%)$, and 1 was exposed to shotgun injury $(1.72 \%)$. From 103 patients over 45 years of age; 80 were exposed to fall $(77.67 \%), 8$ were exposed to injury within the vehicle $(7.77 \%), 6$ were exposed to motorcycle injury $(5.83 \%), 4$ were exposed to injury out of the vehicle $(3.88 \%), 3$ were exposed to sports injury $(2.91 \%), 2$ were exposed to shotgun injury (1.94\%) (Table 1, Figure 2).

When we investigated whole study group, totally 25 patients were exposed to motorcycle injury. There was 1 patient under 15 years of age (4\%), 18 patients between $15-45$ years of age (72\%), and 6 patients over 45 years of age $(24 \%)$ (Table 1). It is stated, motorcycle injuries occur most often in 15-45 years of age group, and it is the first etiological reason with $31.03 \%$ in this age group.

\section{Discussion}

Traffic injuries are a major but neglected global public health problem. Too often, road safety is treated as a transportation issue, not a public health issue. Trafficrelated injuries are often treated as transportation issues, called 'accidents', although most could be prevented (2). Rendering of scientific data about traffic injuries will provide to come over and to prevent this injuries better.

According to the WHO Report of Road Safety 2005, 1.2 million people are killed every year road traffic crashes around the world. Up to 50 million people are injured, many suffering life-long disability (2). Motorcycle crashes continue to be a major cause of fatal road traffic injuries (4). Among these fatal head injuries, bicyclists and motorcyclists represented over $55 \%$ of all victims (2). It is stated as injuries to the head, neck and chest were responsible for most severe injuries. Thoracic and abdominal trauma as well as pelvic ring fractures associated with long bone injuries appears to be the secondary factors contributing to reduced survival (4). A delay in diagnosis and treatment can influence the final outcome significantly. Long bone fractures were the commonest injury accompanying to motorcycle accidents. It is reported as lower and upper extremity, head and thoracic cage are the most affecting parts of the body in motorcycle injuries and the most important variable affecting mortality in motorcycle crashes is head injury (4).

The study of Ankarath et al. (4) thus important to state this condition of the 1239 patients who admitted to various hospitals by motorcycle crash concluded in this study of Ankarath et al., 11.8\% had head and facial injuries, $17.4 \%$ had chest trauma, 12.8 had abdominal trauma, $10.4 \%$ had spinal injury, $94.3 \mathrm{had}$ axial skeletal injury, 0.3 had crush injury, 0.2 had peripheral arterial injury. The detailed distribution of skeletal injuries as follows: $13.2 \%$ had pelvic injuries, $17 \%$ had femoral shaft fractures, $0.3 \%$ had femoral neck fractures, $29.8 \%$ had tibial fractures, $11 \%$ had ankle fractures, 3.7\% had forearm fractures, 5.4\% had humeral fractures, $7.6 \%$ had clavicular fractures, $2 \%$ had scapular fractures, $7.4 \%$ wrist fractures, and $2.7 \%$ had fractures in the hands. 41 of these patients $(4.1 \%)$ were rear seat passengers. Of the 1239 patients requiring hospital admission, 74 died (6\%). The lower thoracic and upper lumbar area of the spine was the most common site of involvement. Thoracic spine fractures are more likely to be associated with neurological damage, but mortality is more highly associated with cervical spine involvement (4).

Correspondingly, in a prospective analysis of the injuries of off-road competition motorcyclists (3), it is reported as $10 \%$ received injuries that required attention from a medical response unit, the majority $(85 \%)$ of those injuries sustained a mild injury when the Injury Severity Score (ISS) is to be considered, $54 \%$ of those injured were first year rookies, speeds were below $50 \mathrm{~km} / \mathrm{h}$ in the majority of accidents $(80 \%)$, the most frequently injured anatomical regions were the extremities $(57 \%)$, the most common types of injury were ligamentous $(50 \%)$, and the most common fractures were those of the foot and ankle (36\%). Speeds and experience were not statistically correlated with severity. In the street riders, ISS are found to be higher significantly than the off-road competition motorcyclists $(3,7)$.

In our study, the patient population consisted of patients operated for the fracture who survived after trauma. Therefore, these numbers consist of patients who had fractures that need operation, not whole admissions to hospitals caused by the etiological factors of trauma. In our opinion, this is the appropriate group for this purpose. If we investigate the etiological factors, fall seems to be the major cause of the fractures in both groups. We think in older population these fractures occur mostly due to simple falls in osteoporosis background. The road accidents, except motorcycle injuries, are discussed separately in our study group as accidents within and out of the vehicle. Thus these ratios are low. When the two groups reviewed together the road accidents were 24\% in 2002 , and were $19.2 \%$ in 2007 . Sports injuries are sited in lower grades in both time periods. One of the important factors for this issue is our study group which consist only fractured and operated patients. Simple ligamentous injuries and ligamentous injuries that required operation have not been considered in our study groups. When two groups compared, $0.075 \%$ decrease in falls, $0.023 \%$ decreases in injuries within the car, $0.013 \%$ decrease in injuries out of the car, $0.616 \%$ decrease in sports injuries, $0.25 \%$ decrease in shotgun injuries is reported. While in 2002 motorcycle injuries were in fifth place with $4 \%$ percentage, it took second place in 2007 with $17.7 \%$. 
Those changes in all etiological factors except motorcycle injuries, is found not statistically significant (Chi-square Test, $\mathrm{p}=0.057$ ). However, those increase in motorcycle injuries is found statistically significant (Ficher Exact Test, $p=0.016$ power $=80 \%$ ). The major cause of this increase seems to be the growing number of riding motorcycles due to multiple reasons. Between these periods, there is a 1.7 times increase in registered motorcycle number according to Transport Authority of İzmir database.

The empirical results presented show the important contribution of economic development to mobility, which leads to increased motorization and increased exposure to risk (2). Parallel to this increase, the infrastructure and the security of the roads must be redesigned. Technical and mechanical training of the motorcycle riders must be developed and supervised.

The authors conclude that measures to prevent injury are more important than improved treatment (4). As follows, the significant difference in the GCS between the patients wearing helmets and the un-helmeted group supports the continued use of a protective headgear (4).Therefore, we think it is necessary to wear helmets, shoulder pads, chest protectors, gloves, hip and knee pads, under roost protectors, and hipknee pad supported boots. Li et al. reported the major morbidity in road traffic injuries affected the $15-44$ year age group. Also they reported, the morbidity of children up to the age of 15 years represented $3.40 \%$, morbidity in the $15-44$ year age group was $64.86 \%$; it was 70.46, in the 45-65 year age group, which accounted for $25.65 \%$ (2).

We reviewed our study group according to the age intervals to reveal the importance of the trauma causes (Figure 2-3). Accordingly, fall is stated in first place with a $68.42 \%$ under 15 years of age group, while injuries out of the vehicle took the second place with $15.79 \%$, and sports injury was third with $10.52 \%$. This age group is tended to be the most dense time period of falls and injuries either caused by both playing and sports. In addition, it is a more likely situation that the children to interpose road traffic injuries as pedestrians. When over 45 years of age group has been investigated, falls take first place with a $77.67 \%$, while injuries within the vehicle is at second place with a $7.77 \%$, and motorcycle injuries is the third with a $5.83 \%$. As the fractures due to simple falls based on osteoporosis becomes prevalent over 55 years of age, consists of this age group, it is rendered falls the major cause in this group. In 15-45 years of age group, the motorcycle injuries are at first place with a $31.03 \%$, while falls and injuries within the vehicle at second place with $27.59 \%$, and injuries out of the vehicle in the third place with $10.34 \%$. This age interval involves the most frequent use of motorcycles, thus it is critically important that states motorcycle injuries role in trauma etiologies. And the overall rates are substantially high. In addition, the intensity of situation manifests was clearer. The motorcycle injuries stand at first place in trauma etiologies, owing to the fact that we split the road traffic injuries as injuries within the vehicle and injuries out of the vehicle. If these injuries have reviewed together; the road traffic injuries have been at the first place and motorcycle injuries at the second in trauma etiologies. But it is more important that motorcycle injuries solely, have considerably approximate to road traffic injuries in this age group and in its present form, it is so wide, that it could not be considered in road traffic injuries. Therefore it supports our theory that motorcycle injuries must be reviewed separately from the road traffic injuries. Additionally, when the patient groups subjected to motorcycle injuries have been reviewed in figure 2 , it has been stated that $4 \%$ of these are under 15 years of age, $72 \%$ are between 15 45 years of age, and $24 \%$ are over 45 years of age. Although, the most prevalent period of motorcycle injuries seems to be between 15-45 years of age, it is the first etiological factor of this age group with $31.03 \%$.

The weak side of our study is the limited number of patient population because of our emergency clinic does not have an appropriate and attainable database of referred patients. However, this study captures the population's numerical and periodical section in a real and true manner, and puts an emphasis on importance and results of this increase.

\section{Conclusion}

As a result, it is noteworthy that, motorcycle injuries show a statistically significant increase, affect the younger patient population, and mostly cause polytraumatic injuries. Therefore, we think that, while trauma etiologies are counted, motorcycle injuries must be reported separately from the road traffic injuries in the studies. In recent years, motorcycle injuries have been added to the etiological factors of traumatic injuries and became a more serious problem in our country. In view of this problem, necessary precautions and attention of our society must be taken.

Conflict of Interest: The authors declare no potential conflicts of interest with respect to the research, authorship, and/or publication of this article.

Ethical issues: All Authors declare that Originality of research/article etc... and ethical approval of research, and responsibilities of research against local ethics commission are under the Authors responsibilities. The study was completed due to defined rules by the Local Ethics Commission guidelines and audits.

Aknowledgement: We thank Assistant Professor Mehmet Orman for helping us in statistical analysis of this study. 


\section{References}

1. Reich RM, Nantulya MV. Equity dimensions of road traffic injuries in low- and middle-income countries. Injury Control and Safety Promotion 2003;10:13-20

2. Yan-Hong L, Rahim Y, Wei L, Gui-Xiang S, Yan Y, De Ding $Z$, et al. Pattern of traffic injuries in Shangai :implications for control. Injury Control and Safety Promotion 2006;13:217-225.

3. Colburn TN, Meyer DR. Sports Injury or Trauma? Injuries of the competetion off-road motorcyclist. Injury 2003;34:207-14

4. Ankarath S, Giannoudis PV, Barlow I, Bellamy MC, Matthews SJ, Smith RM. Injury patterns associated with mortality following motorcycle crashes. Injury 2002;33:473-77.

5. Peek C, Braver ER, Shen H, Kraus JF. Lower extremity injuries from motorcycle crashes. A common cause of preventable injury. J Trauma 1994;37(3):358-64.

6. Sinha AK, Boot DA, Gorman DF, Teanby DN. Severe motorcycle injury in Mersey region and North Wales. Injury 1995;26:543-5

7. Sood S. Survey of factors influencing injury among riders invoved in motorized two-wheeler accidents in India:a prospective study of 302 cases. J Trauma 1988;28:530-4

8. Pai, Chih-Wei and Saleh,Wafaa. Exploring Motorcyclist Injury Severity Resulting from Various Crash Configurations at T-Junctions in the United Kingdom - An Application of the Ordered Probit Models. Traffic Injury Prevention, 2007;8:62-8

9. Ceylan S, Açıkel C H, Dündaröz R, Yaşar M,Güleç M, Özışık T. Bir Eğitim Hastanesi Acil ServisineTravma Nedeniyle Başvuran Hastaların Sıklığının Ve Travma Özelliklerinin Saptanması. Turkiye Klinikleri J MedSci 2002, 22:156-161

Copyright (C) 2014 The Author(s); This is an open-access article distributed under the terms of the Creative Commons Attribution License (http://creativecommons.org/licenses/by/4.0), which permits unrestricted use, distribution, and reproduction in any medium, provided the original work is properly cited. All Rights reserved by international journal of Medical Science and Discovery. 